\title{
A NEW PHENOMENON IN THE SUPERCONDUCTING TRANSITION OF TANTALUM AND OF TIN
}

\author{
By Francis B. Silsbee, Russell B. Scott, and Ferdinand G. Brickwedde
}

\section{ABSTRACT}

The transition from the superconducting to the normal resisting state under certain conditions is found not to be continuous but to include a hitherto unsuspected spontaneous increase in resistance followed by a slower decrease. The spontaneous decrease in resistance usually proceeds for several minutes in a succession of steps until only a fraction of its crest value remains. This crest value of the transient resistance is sometimes 75 percent of the normal. After such an effect has occurred, it will not occur again when the same conditions are reestablished, unless, in the meantime, the temperature has been lowered or else a time interval of at least half an hour has elapsed.

These spontaneous changes in resistance can be initiated by a step upward in temperature, in current, or in magnetic field and proceed thereafter, as described above, while all three external conditions are maintained constant. The combination of temperature, field, and current at which this phenomenon appears has been studied, and the progress of the resistance change under various conditions noted. The effect is pronounced only when the current is relatively large (about $2 \mathrm{amp}$ in the tin wire, diameter $0.022 \mathrm{~cm}$ ).

The transition temperatures of two specimens of hard-drawn tantalum wire were found to be 3.961 and $4.068^{\circ} \mathrm{K}$, respectively. The presence of a transverse magnetic field depressed the transition temperature at a rate of $1^{\circ} \mathrm{K}$ per 1,250 oersteds.

\section{CONTENTS}

I. Introduction _.

II. Characteristics of specimens

III. Nature of overshoots

IV. Magnitude and speed of overshoots _...

V. Persistence of resistance after an overshoot.

VI. Secondary overshoots__._.

VII. Interrupted overshoots

VIII. Conditions for producing overshoots

IX. Discussion _.

\section{INTRODUCTION}

In recent experiments at the National Bureau of Standards, in which currents of sufficiently large value have been caused to flow in wires of tantalum and of tin, while the temperature, external magnetic field, or current was gradually changed so that the material passed from the superconducting to the normal resisting state, it was found that there was a transient appearance of resistance which spontaneously disappeared. As conditions were further changed the resistance made a second and permanent reappearance. For lack of a better term we here refer to this sudden and temporary increase of resistance followed by a decrease as an "overshoot." It is the purpose of this paper to describe these overshoots in some detail, and to set forth the conditions under which they were found to occur. 
When the tin specimen was caused to pass from the superconducting to the normal resisting state by increasing the current, the value of the current required to produce the transition was such as to produce at the surface of the wire a magnetic field which, of itself, in the absence of the current, would restore the resistance. ${ }^{1}$ On the other hand, both of the tantalum specimens studied exhibited a further anomaly, in that the permanent restoration of resistance by a current in the specimen occurred at a value of current much smaller than would have been expected from the magnetic field normally required to restore resistance. A similar anomaly has been noted in several alloys ${ }^{23}$ and has recently been reported in "fairly pure" tantalum by Mendelssohn and Moore. ${ }^{4}$ The fact that the normal tin specimen shows the transient overshoot effect in similar fashion to the abnormal tantalum would seem to indicate that the overshoot phenomenon is a general property of all superconductors and is not a peculiarity of the particular tantalum specimens in which we first observed it.

In this work the temperatures were deduced from the vapor pressure of the liquid helium bath in which the specimens were immersed. The results have been reduced to the Leiden scale of absolute temperatures by using the vapor-pressure formula $\log _{10} p=-3.024 / T+$ $2.208 \log _{10} T+1.217$ given in Leiden Communication no. 202, where $p$ is the vapor pressure in centimeters of mercury and $T$ is the absolute temperature. The values have been carried out to the nearest $0.001^{\circ} \mathrm{K}$, because differences may be significant to this precision even if the absolute value of temperature is not.

The term "resistance" is used merely to denote the quotient obtained by dividing the difference of potential at the terminals of the specimen by the (direct) current flowing in it, without intending to imply that Ohm's law is obeyed. The difference of potential was observed directly by the deflection of a seinsitive galvanometer connected to potential leads attached to the specimen near its ends. Suitable shunt and series resistors were used as needed to reduce the sensitivity of the galvanometer. Except where noted specially, the current through the specimen was not interrupted or reversed during the course of any one experiment. When necessary, small corrections for spurious thermoelectromotive forces were applied on the basis of the deflections observed when the current circuit of the specimen was open just before and just after an experiment.

\section{CHARACTERISTICS OF SPECIMENS}

Table 1 gives a summary of the more important characteristics of the three specimens examined. The tin wire was formed from an ingot of NBS "standard sample" material ( $99.99 \%$ pure) by extruding it at about $170^{\circ} \mathrm{C}$ through a steel die. The tantalum specimens were purchased in the form of hard-drawn wires from the Fansteel Co., in 1933. A spectrochemical analysis ${ }^{5}$ of wire from the same spool as specimen $95 \mathrm{Ta}$ indicated only small amounts (probably not over a few tenths percent) of $\mathrm{Sn}$ and $\mathrm{Si}$ and traces of $\mathrm{Fe}, \mathrm{Ca}, \mathrm{Cl}$, and $\mathrm{Cb}$. In view of this, the abnormally low transition temperatures and high

\footnotetext{
1 This relation was suggested many years ago by one of the authors and has been confirmed by workers at Leiden for several pure metals. See Tuyn, J. Franklin Inst. 201, 379 (1926).

2 W. H. Keesom, Physica 2, 35 (1935). Leiden Comm. No. 234f.

3 Rjabinin and Shubnikov. Physik Z. Sowjet-Union 7,122 (1935).

1 Nature 135,826 (1935).
This analysis was carried out by B. F. Scribner, to whom the authors are greatly indebted.
} 
resistance ratio " $r$ " of these specimens are more probably caused by internal strain rather than by impurities.

TABLE 1.-Characteristics of specimens

\begin{tabular}{|c|c|c|c|}
\hline & \multicolumn{3}{|c|}{ Specimen } \\
\hline & $8 \mathrm{Sn}$ & $95 \mathrm{Ta}$ & $10 \mathrm{Ta}$ \\
\hline Diameter of wire, $\mathrm{cm}$ & 0.022 & 0.0075 & 0.0127 \\
\hline Length (approx.), cm. & 225 & 210 & \\
\hline Material of supporting tube............. & Paper & Glass & Paper \\
\hline Resistance at room temperature, $R_{1}$, ohms. & 8.3 & 95.0 & 10.6 \\
\hline 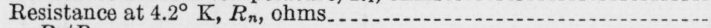 & 0.0081 & 25.0 & 2.83 \\
\hline$r=R_{n} / R_{1} \ldots$ & 0.00098 & a 0.26 & ${ }^{a} 0.26$ \\
\hline Transition temp $\left(R=R_{n} / 2\right.$, small $\left.I\right)$, ${ }^{\circ} \mathrm{K}$ & 3.724 & a 3.961 & a 4.068 \\
\hline Transition range $\left(0.1 R_{n}\right.$ to $\left.0.9 R_{n}\right)$, ${ }^{\circ} \mathrm{K}$ & 0.023 & 0.050 & 0.055 \\
\hline Magnetic field per $1^{\circ} \mathrm{K}$ depression of the transition, oersteds ${ }^{6}$ & 116 & 1,250 & 1,020 \\
\hline Current per $1^{\circ} \mathrm{K}$ depression of the transition, observed, amp..... & 6.86 & 0.95 & 1.89 \\
\hline Current per $1^{\circ} \mathrm{K}$ depression of the transition, ealculated, amp....... & & 23.4 & 32.3 \\
\hline
\end{tabular}

- Meissner, Z. Physik 61, 191 (1930), finds $r=0.050$ and $T=4.38$ for his purest sample.

The effect of a transverse magnetic field in depressing the transition temperature was studied in some detail in $95 \mathrm{Ta}$ with the results shown in figure 1, in which the resistance is plotted against magnetic

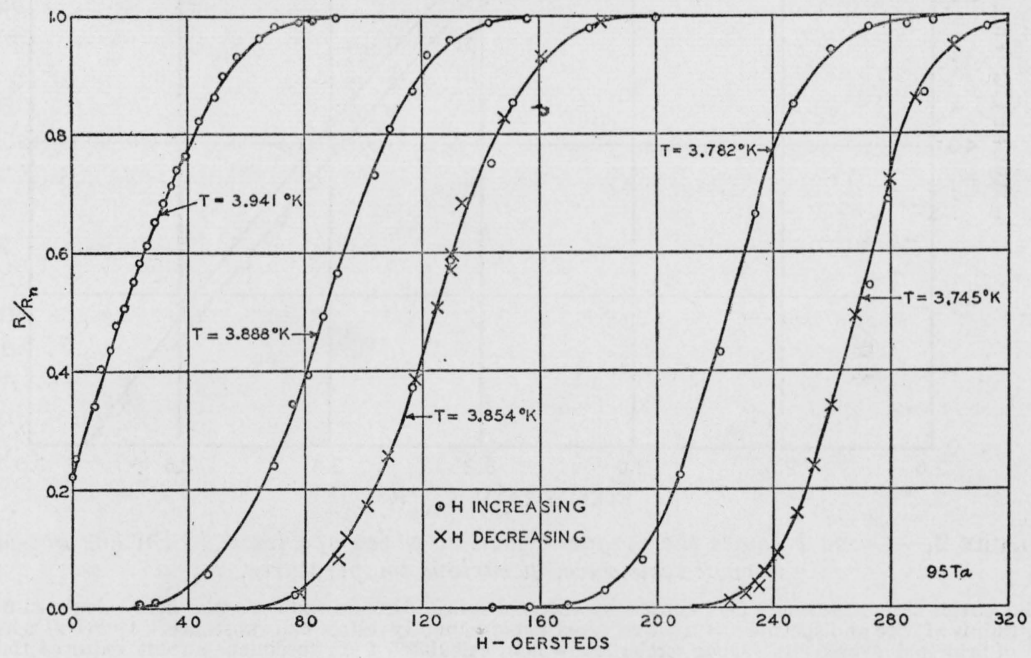

FigURE 1.-Variation with transverse magnetic field of the resistance.

Variations are expressed as a fraction of the normal resistance above the transition range as measured with $1 \mathrm{ma}$ (specimen $95 \mathrm{Ta}$ ) at various temperatures.

field for several different temperatures. These data show no measurable hysteresis. A single measurement on $10 \mathrm{Ta}$, incidental to other work, indicated that it had about the same $d H / d T$ as $95 \mathrm{Ta}$. The tin sample showed hysteresis effects amounting to several oersteds. ${ }^{6}$

In figure 2 the solid circles show the external transverse field for half resistance at various temperatures, while the crosses show the

\footnotetext{
- In accordance with the formal action of the International Electrotechnical Commission in 1930 and of the International Union of Pure and Applied Physics, in 1932, we here use the name "oersted" for the cgs unit of magnetic-field intensity in place of the name "gauss", which is still frequently used for both this unit and that of magnetic-flux density.
} 
values ${ }^{7}$ of $2 I_{s} / 10 a$, where $a$ is the radius of the wire and $I_{s}$ is the specimen current in amperes just sufficient to permanently restore half resistance. The precision in locating these points is considerably lessened by the transient effects to be mentioned below. Their systematic deviation from the line showing the effect of the external transverse field may perhaps result from an error in the measurement of the wire diameter. The agreement between the two sets of points is on the whole fairly close and strongly suggests that in this specimen

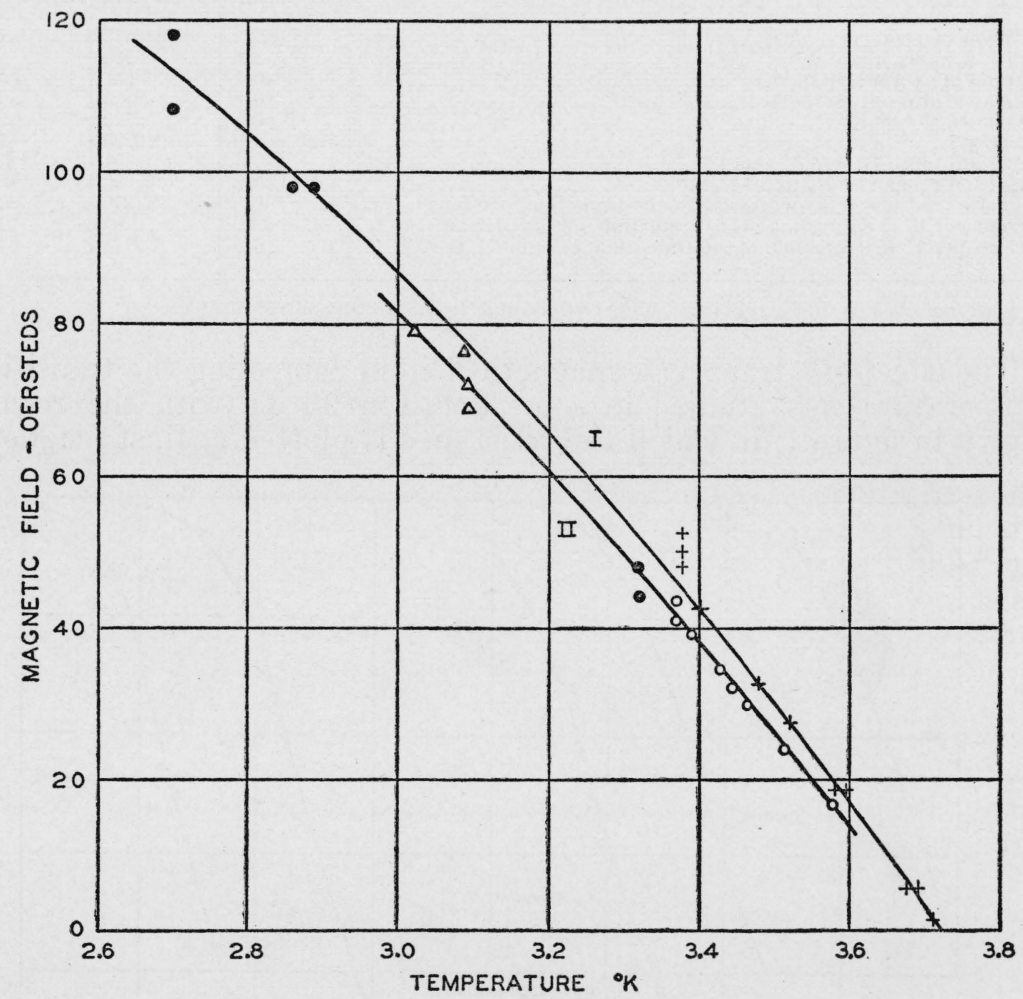

Figure 2.-Curve I shows the magnetic field at which specimen 10 Sn has one-half normal resistance, at various temperatures.

Solid circles show transverse field caused by external coils. Crosses show circular field calculated from radius of wire and specimen current required to permanently restore half resistance. Curve $I I$ is locus of principal overshoots. Open circles show field calculated from specimen current required to initiate a principal overshoot. Open triangles show sum of external and specimen-current fields required to initiate principal overshoot.

the permanent restoration of resistance by the large currents is the result of the magnetic field which they produce.

In the tantalum specimens the effect of current in permanently disturbing the superconduction is shown in table 1 and also in figure 12, by the difference in trend of curves $I$ and $V$. A small current is obviously far more effective in disturbing the superconduction than would be expected from its magnetic field.

The possibility that this abnormal sensitivity to current is a spurious result of a heating of the specimen above the temperature of the bath

7 This quantity is of course the maximum intensity of the (circular) magnetic field produced at the surface of the wire by the current itself, if the current is distributed uniformly over the area or around the periphery of the wire. 
was carefully studied but finally dismissed. The fact that the bare wire is in intimate contact with the liquid helium, the fact that the width of the transition range is substantially the same at large and small currents, and the fact that the depression in transition temperature varies in proportion to the current rather than to its square, all conspire to render this explanation very improbable.

\section{NATURE OF OVERSHOOTS}

The curious nature of the overshoots can best be made clear by following the course of a particular experiment. With specimen $95 \mathrm{Ta}$ immersed in a bath of liquid helium held at a constant temperature of $3.877^{\circ} \mathrm{K}$, and with no external magnetic field (other than terrestrial), the resistance when measured with a current of 1 ma was 0.0026 ohm. As the current was increased the potential difference increased at a still faster rate so that at $10 \mathrm{ma}$ the resistance was $0.01 \mathrm{ohm}$; at $12 \mathrm{ma} 0.024 \mathrm{ohm}$; and at $13 \mathrm{ma} 0.059 \mathrm{ohm}$. After a few seconds, however, the resistance, with $13 \mathrm{ma}$ still flowing, had decreased to $0.051 \mathrm{ohm}$, at which value it became steady. This small spontaneous change in resistance may be called a preliminary overshoot. As the current was further increased the resistance rose gradually so that at $16 \mathrm{ma}$ it was $0.085 \mathrm{obm}$ and at $24 \mathrm{ma}$ it was $0.20 \mathrm{ohm}$. However, when the rheostat in series with the specimen was adjusted so that the current increased to $25 \mathrm{ma}$, the galvanometer made a rapid excursion in a few seconds to a deflection which corresponded to a resistance of $17.0 \mathrm{ohms}$. As a result of this rise in resistance the current decreased to a minimum of $23.3 \mathrm{ma}$. The resistance began to fall again at once and in the course of a minute had decreased to $4.0 \mathrm{ohms}$, and the current had correspondingly risen to $24.7 \mathrm{ma}$. This spontaneous change may be called the principal overshoot. Further gradual changes in the rheostat setting raised the current to $25.5 \mathrm{ma}$ without stimulating another overshoot, and the specimen then showed a resistance of only $3.5 \mathrm{ohms}$.

The current was then reduced to $15.6 \mathrm{ma}$ and the resistance then found to be only $0.08 \mathrm{ohm}$. On again restoring the current to $25.5 \mathrm{ma}$, the resistance was only $0.11 \mathrm{ohm}$. Further increase in current showed $0.12 \mathrm{ohm}$ at $27.5 \mathrm{ma}$ and $0.16 \mathrm{ohm}$ at $31.0 \mathrm{ma}$. A few seconds after this last reading was obtained, the resistance of the specimen again rose spontaneously to a crest value of $10 \mathrm{ohms}$, from which it immediately decreased, at first rapidly and then more slowly and with evident pauses at $7.1 \mathrm{ohms}$ and at $6.2 \mathrm{ohms}$, to an apparently steady value of $2.9 \mathrm{ohms}$. Overshoots occurring subsequent to the principal overshoot, such as this later spontaneous change, may be called secondary overshoots.

The foregoing experiment involved an increase in specimen current at constant temperature and constant external magnetic field. Similar overshoots occur if the temperature is increased at constant current and field or if the externally applied field is increased at constant current and temperature, provided the specimen current is sufficiently high. Figure 3 gives a transition curve for specimen $95 \mathrm{Ta}$ in which the temperature was varied. This curve does not happen to show any preliminary or secondary overshoots.

When the procedure was reversed and the specimen passed from the normal resisting to the superconducting state as a result of a decrease in temperature, field, or current, no abnormality was observed. 


\section{MAGNITUDE AND SPEED OF OVERSHOOTS}

If the final increment which stimulates the overshoot is very slight, the rate of rise of resistance is so slow that it can be followed even by the galvanometer used in this work, which had an (undamped) natural period of 4 seconds, but which was used with a shunt of such low resistance as to make it considerably overdamped.

If the variable is increased suddenly to a value considerably above the critical, both the increase and the initial stages of the decrease in resistance occur more rapidly, with the result that the maximum deflection of the galvanometer falls short of ind icating the true maximum value of resistance attained. The rate at which the current, field, or temperature is changed prior to reaching the critical value,

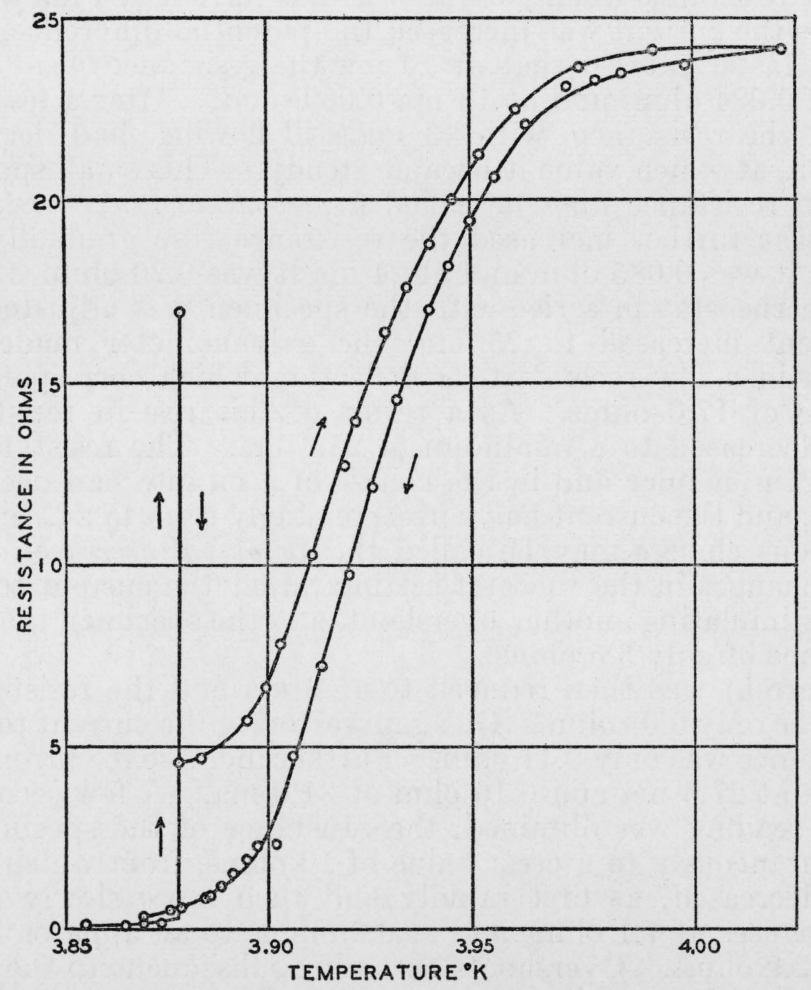

FIGURE 3.-Typical principal overshoot and transition obtained by varying temperature of specimen $95 \mathrm{Ta}$.

does not seem to affect the overshoot. Figure 4 shows the resistancetime relation for a number of overshoots observed in specimen $95 \mathrm{Ta}$ and figure 5 for an overshoot of the tin specimen $8 \mathrm{Sn}$. The maximum resistances observed in $95 \mathrm{Ta}$ were sometimes approximately equal to the full normal resistance of the specimen but have never been found to exceed this resistance, even when the suddenly applied current was nearly four times the minimum value required to start an overshoot. They are more usually 25 to 50 percent of the normal resistance. In the case of specimen $10 \mathrm{Ta}$, the magnitude of the principal overshoots was notably less than in the case of $95 \mathrm{Ta}$, being usually about 14 
percent of the normal resistance. In $8 \mathrm{Sn}$, the resistance at the crest of the overshoot was about 50 percent of the normal resistance.

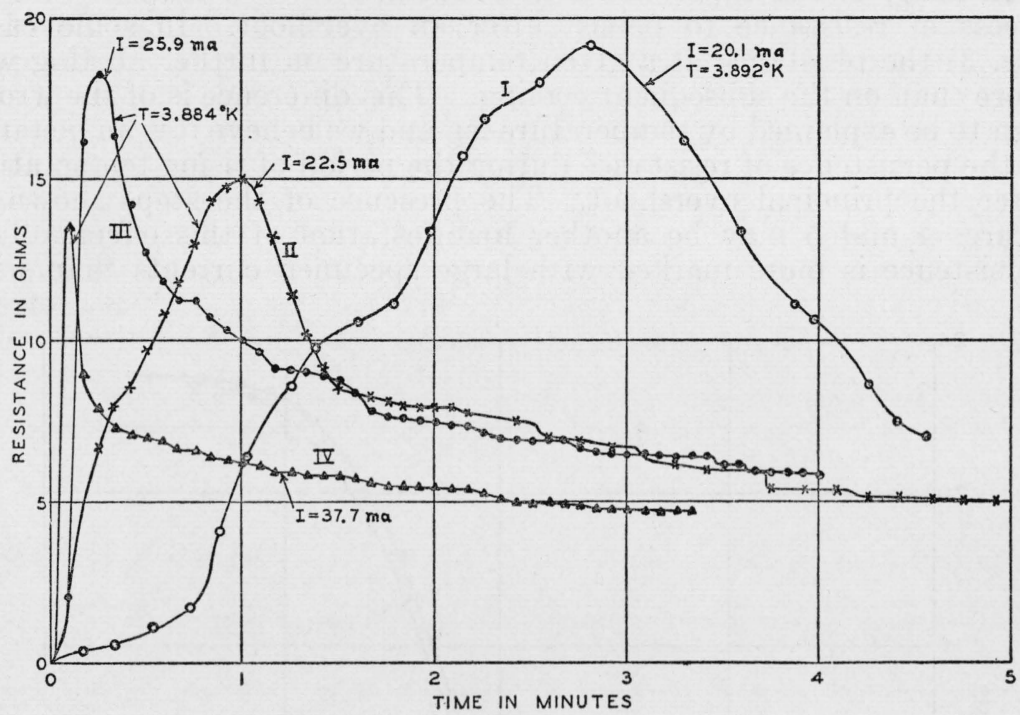

Figure 4.-Typical overshoots in specimen $95 \mathrm{Ta}$, after a current of the value marked on each curve has been suddenly applied.

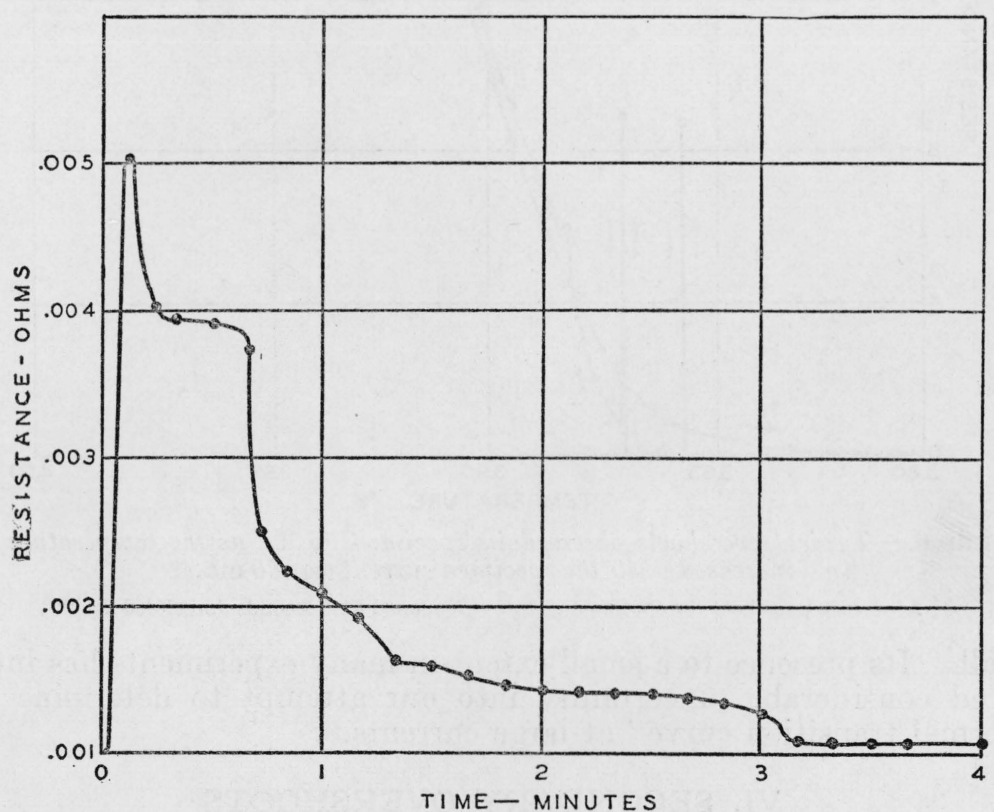

FIGURE 5.-Typical overshoot in specimen $8 \mathrm{Sn}$ while held at $3.425^{\circ} \mathrm{K}$ when current was raised to $1.9 \mathrm{amp}$.

Figures 4 and 5 also show the definitely "stepped" character of both the increase (when it is slow enough to be observable) and the decrease in resistance. 


\section{PERSISTENCE OF RESISTANCE AFTER AN OVERSHOOT}

In many of our experiments there seemed to be a tendency for an excess of resistance to persist after an overshoot. In some cases (fig. 3) the resistance at a given temperature on further heating was more than on the subsequent cooling. This difference is of the wrong sign to be explained by temperature lag and we believe it is an instance of the persistence of resistance during the period of rising temperature after the principal overshoot. The presence of the steps shown in figures 4 and 5 may be another manifestation of this effect. This persistence is more marked with large specimen currents than with

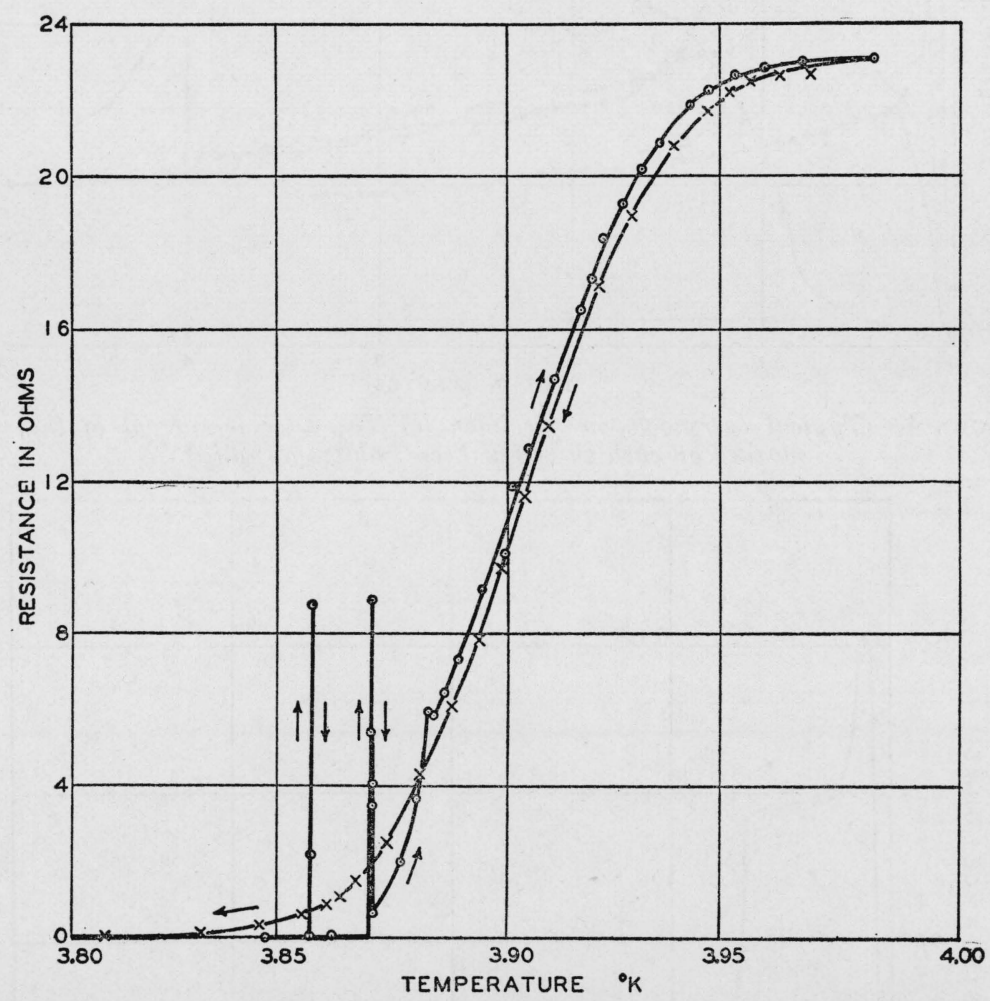

FiguRE 6.-Typical overshoots observed in specimen $95 \mathrm{Ta}$ as the temperature was increased while the specimen current was 50 ma.

After each overshoot the specimen circuit was opened for 2 seconds and closed again.

small. Its presence to a small extent in many experiments has introduced considerable uncertainty into our attempt to determine the "normal transition curve" at large currents.

\section{SECONDARY OVERSHOOTS}

After an overshoot has occurred and the resistance has settled down to a nearly constant value, the variable which stimulated the principal overshoot may be further increased. If this increase is made in abrupt steps, each sudden increase in the independent variable (that is, 


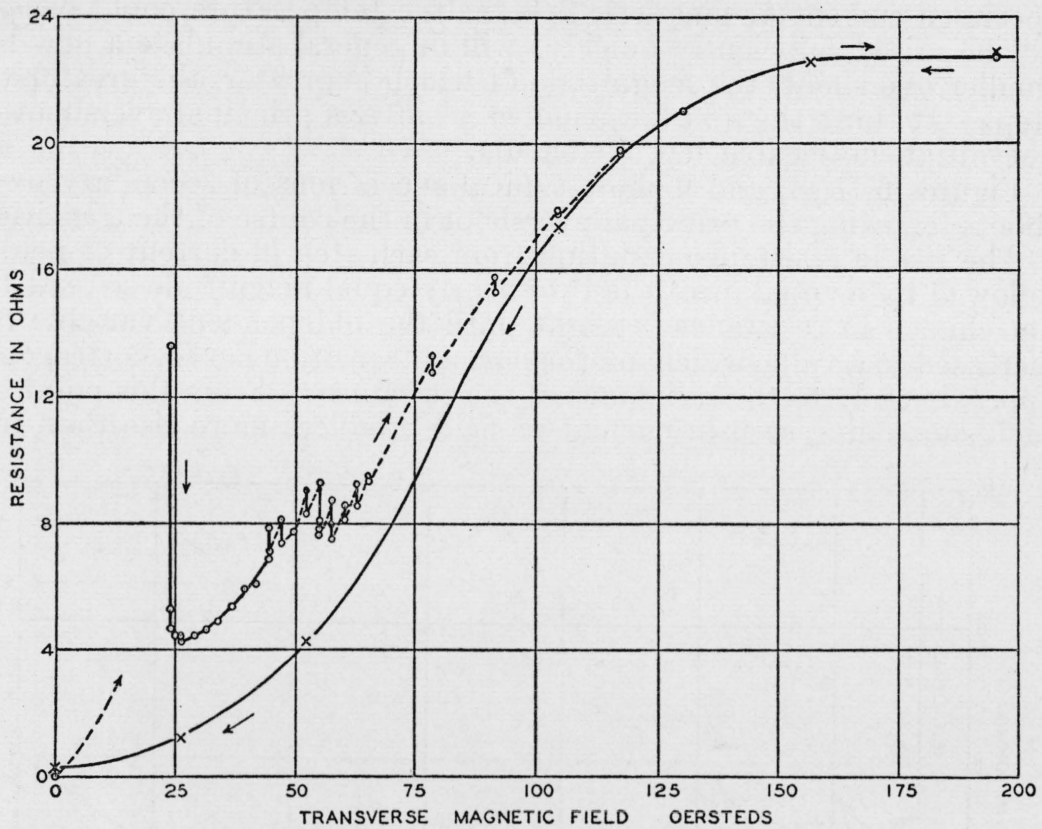

FigURe 7.-Typical principal and secondary overshoots observed in specimen $95 \mathrm{Ta}$ as the external transverse magnetic field was increased while the current in the specimen was $30 \mathrm{ma}$ and the temperature was $3.832^{\circ} \mathrm{K}$.

The specimen circuit was left closed throughout the experiment.

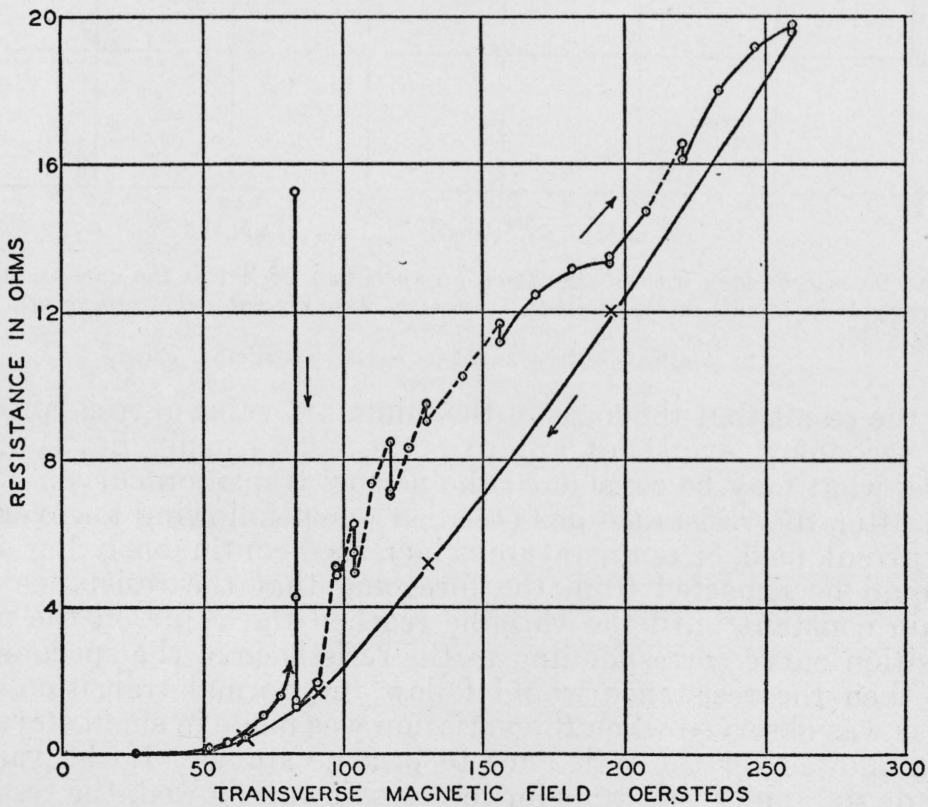

FIGURE 8.-Typical principal and secondary overshoots observed in specimen $95 \mathrm{Ta}$ as the external transverse magnetic field was increased while the current in the specimen was $30 \mathrm{ma}$ and the temperature was $3.749^{\circ} \mathrm{K}$.

After each overshoot the specimen circuit was opened for 2 seconds and again closed. 
specimen current or magnetic field, as the temperature could usually not be raised sufficiently quickly) will in general stimulate a new but smaller overshoot, the magnitude of which is greater, the greater the step. At times the first few small steps after a principal overshoot do not initiate noticeable new overshoots.

Figures $6,7,8$, and 9 show typical successions of secondary overshoots following the principal overshoot in the course of the transition.

The rise in resistance resulting from each step in current or field is followed by a spontaneous fall ${ }^{8}$ of nearly equal magnitude so that the net change in resistance is slight until the independent variable has increased to a value which, on the normal transition curve, corresponds approximately to the resistance of the specimen. From this point on, each succeeding step in current or field produces more rise than fall,

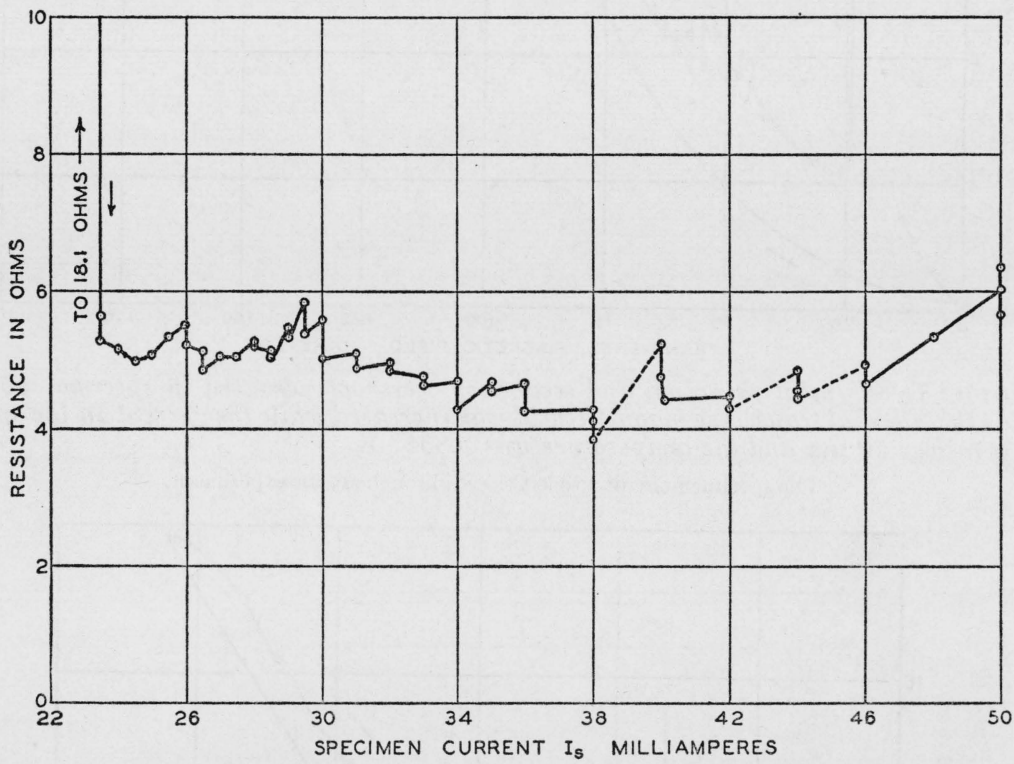

Figure 9.-Secondary overshoots shown by specimen $95 \mathrm{Ta}$ as the current in it was increased in small steps without opening the circuit, the temperature being $3.894^{\circ} \mathrm{K}$.

The principal overshoot at 23.5 ma reached a crest of $18.1 \mathrm{ohms}$.

with the result that the locus of the minimum value of resistance after each secondary overshoot approximates, but usually lies somewhat above, what may be considered the normal transition curve.

If, after the resistance has steadied down following an overshoot, the current, field, or temperature is increased continuously but slowly, it would be expected from the foregoing that the resistance would remain constant until the variable reached the value on the normal transition curve corresponding to the resistance of the specimen and that then the resistance would follow the normal transition curve, just as was observed when the variation was made in small steps, time being allowed for the resistance to become stable. If the variation is made so rapidly that time for recovery is not allowed, the resistance

8 This fall may in part be a further decrease in the resistance persisting from the principal overshoot. The sum of the falls during a succession of secondary overshoots, how ever, often exceeds the resistance persistin $\mathrm{g}$ after the principal overshoot. 
would be expected to rise as the current, field, or temperature is varied and the transition curve to lie above the normal curve but to approach it, as shown in figure 3. These expectations were borne out by the experiments.

In table 2 are summarized the results of a number of experiments in which the increase of current, field, or temperature has been carried nearly to the value needed to restore normal resistance. The first four columns indicate the experimental conditions, the entry "var" indicating the variable which was increased during the experiment. In those marked circuit "opened" the current through the specimen was interrupted for about 2 seconds after each secondary overshoot. In those marked "closed" the circuit through the specimen was kept closed throughout the experiment. The column headed "percent total increase" gives the sum of all the increases in the resistance observed in the course of the experiment, to which has been added (when necessary) the differences between the full normal resistance and the resistance at the point where the experiment terminated, the total being expressed as a percentage of the normal resistance. It will be noted that the sum of the separate increases seems to approach a value double the normal resistance of the specimen and that while it falls somewhat short of this limit in many experiments, it exceeds it by a significant amount only in the two experiments marked with an asterisk, which will be discussed later, footnote 10 .

$T_{A B L E} 2 .-S u m m a t i o n$ of increases in resistance during transition

\begin{tabular}{|c|c|c|c|c|c|c|c|c|c|}
\hline $\begin{array}{c}\text { Tempera- } \\
\text { ture }\end{array}$ & Current & Field & Circuit & $\begin{array}{c}\text { Total } \\
\text { increase }\end{array}$ & $\begin{array}{l}\text { Tempera- } \\
\text { ture }\end{array}$ & Current & Field & Circuit & $\begin{array}{c}\text { Total } \\
\text { increase }\end{array}$ \\
\hline \multicolumn{5}{|c|}{ SPECIMEN $95 \mathrm{Ta}$} & \multicolumn{5}{|c|}{ SPECIMEN $10 \mathrm{Ta}$} \\
\hline${ }^{\circ} \mathrm{K}$ & amp & $\begin{array}{l}\text { Oer- } \\
\text { steds }\end{array}$ & & $\%$ & ${ }^{\circ} \mathrm{K}$ & amp & $\begin{array}{l}\text { Oer- } \\
\text { steds }\end{array}$ & & $\%$ \\
\hline var & 0.030 & 0 & Opened..... & \multirow{5}{*}{$\begin{array}{r}208 \\
171 \\
190 \\
{ }^{*} 236 \\
{ }^{*} 274 \\
176\end{array}$} & 3.994 & var & 0 & Closed. & 152 \\
\hline 3.758 & .030 & var & do do & & var & 0.200 & 0 & Opened. & 121 \\
\hline 3.758 & .060 & $\operatorname{var}$ & do & & 3. 962 & var & 0 & ..... do & 144 \\
\hline 3. 862 & var & 0 & ndo & & & & & & \\
\hline 3.880 & var & $\begin{array}{l}0 \\
0\end{array}$ & .....do_......... & & \multirow{2}{*}{\multicolumn{5}{|c|}{ SPECIMEN 8 Sn }} \\
\hline 3. 718 & .000 & $\mathrm{var}$ & do & & & & & & \\
\hline 3.840 & .030 & var & Closed & \multirow{2}{*}{$\begin{array}{l}179 \\
137 \\
185\end{array}$} & & & & & \multirow[b]{2}{*}{195} \\
\hline 3.894 & vara & 0 & _.... do & & 3.380 & var & 6.5 & Opened. & \\
\hline 3. 894 & $\operatorname{var}^{b}$ & 0 & do do & 167 & $\begin{array}{l}0.000 \\
3.524\end{array}$ & $\begin{array}{l}\text { var } \\
\text { var }\end{array}$ & $\begin{array}{r}0.0 \\
0\end{array}$ & do & 167 \\
\hline 3.897 & var & 0 & ..... do & 191 & 3.384 & var & 13 & do & 141 \\
\hline 3.972 & .030 & var & do & 201 & $\begin{array}{l}3.407 \\
3.407\end{array}$ & var & 0 & do & 182 \\
\hline
\end{tabular}

- Current raised in 4 large steps.

- Current raised in 20 small steps.

After a principal overshoot has once occurred, a moderate decrease of the current through the specimen will produce a very considerable decrease in the resistance, and in particular after the current circuit through the specimen has been opened for about 2 seconds and again closed, the resistance is found to be usually less than 0.5 percent of the full normal value and hence substantially equal to that before the overshoot occurred. Although the resistance is again the same the condition thus produced in the specimen must however be different from that immediately preceding the principal overshoot because now no overshoot results when the current, magnetic field, or temperature is restored to the value which stimulated the original overshoot. Sufficient further increases in current, magnetic field, or 
temperature will however initiate secondary overshoots. In some cases, figure 6 , the value of resistance just prior to one of these secondary overshoots has been found to be less than that estimated for the normal transition, as if the specimen was in an unstable state.

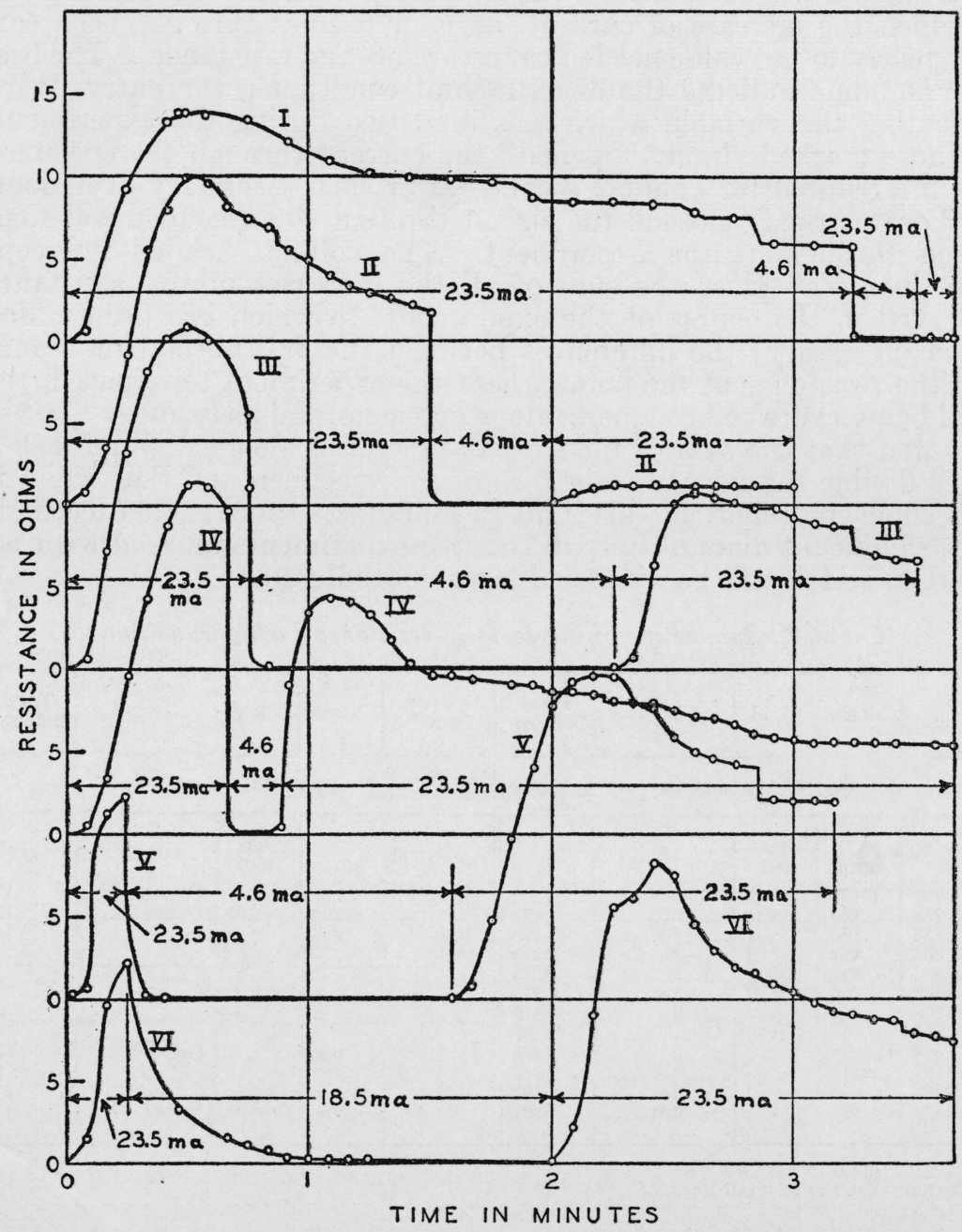

FIGURE 10.-Interrupted overshoots in specimen $95 \mathrm{Ta}$ in which the current was reduced from the initiating value to a lower value during part of the phenomenon and then restored, as indicated by the horizontal dimension lines.

Temperature $=3.886^{\circ} \mathrm{K}$.

Meissner ${ }^{9}$ also has reported a case in which on raising the temperature the resistance remained abnormally low well into the transition range.

• Z. ges. Kälte-Ind. 41, 129 (1934). Physik Z. 37, 449 (1936). 


\section{INTERRUPTED OVERSHOOTS}

A number of experiments were performed with specimen $95 \mathrm{Ta}$ in which a slow overshoot was initiated by applying a current only slightly above the critical, and the overshoot process was then interrupted by suddently reducing the current to a lower value at some time before its completion. After an interval the original value of current was restored and the further change in resistance followed. Figure 10 shows the results. Similar results, not shown in the figure, were obtained in experiments in which the current in the specimen and the temperature were left unchanged, but in which the applied transverse magnetic field was removed quickly during the progress of an overshoot and then restored at a later time. It will be seen that the ability to produce an overshoot at the original current is not lost until the process has gone nearly to completion, and that the overshooting process requires the continued presence of the condition which initiated it, if it is to complete itself.

However, it was found that if the current was supplied by a battery through a circuit having little resistance other than that of the specimen itself, the process went to completion in spite of the automatic decrease in current as the resistance of the specimen rose and the increase in current as the resistance fell.

\section{CONDITIONS FOR PRODUCING OVERSHOOTS}

If the three independent variables, temperature, field, and current, are plotted along three mutually perpendicular axes, the locus of combinations of these variables at which a principal overshoot occurs will constitute a surface in three-dimensional space. This principal critical surface is fairly definite and reproducible and an overshoot will occur, with the exception noted below, if the state point representing the condition of the specimen is caused to move in any manner from the side corresponding to lower values of the variables to the other. The exception is that, as has been already pointed out, after a principal overshoot has taken place, if the state point is brought back through the critical surface by a reduction in current or magnetic field, which is then immediately increased again to its former value, a second overshoot does not occur. A second overshoot at the principal critical surface will occur only if the specimen has been restored to the normal superconducting condition. It was found that a convenient normalizing process was to lower the temperature by about $0.6^{\circ} \mathrm{K}$. This, together with the time for raising the temperature again, lasted about 5 minutes. Fresh principal overshoots were obtained after reducing the temperature only $0.07^{\circ} \mathrm{K}$ below that at which the preceding principal overshoot had occurred. This occupied only 3 minutes. If the temperature was left at the value at which the overshoot occurred and the specimen current was reduced to zero, it was found that the ability to again produce a principal overshoot developed rather slowly. In the case of $95 \mathrm{Ta}$ an interval of 10 minutes sufficed to make possible a second principal overshoot of one-third the previous magnitude, and 25 minutes one of one-half magnitude.

Figure 11 shows for specimen $95 \mathrm{Ta}$ the contours of this principal critical surface for several constant values of $T$. Curve $I V$ of figure 12 is a contour for $H=0$. Curves $I, I I$, and $I I I$, figure 12, show for 


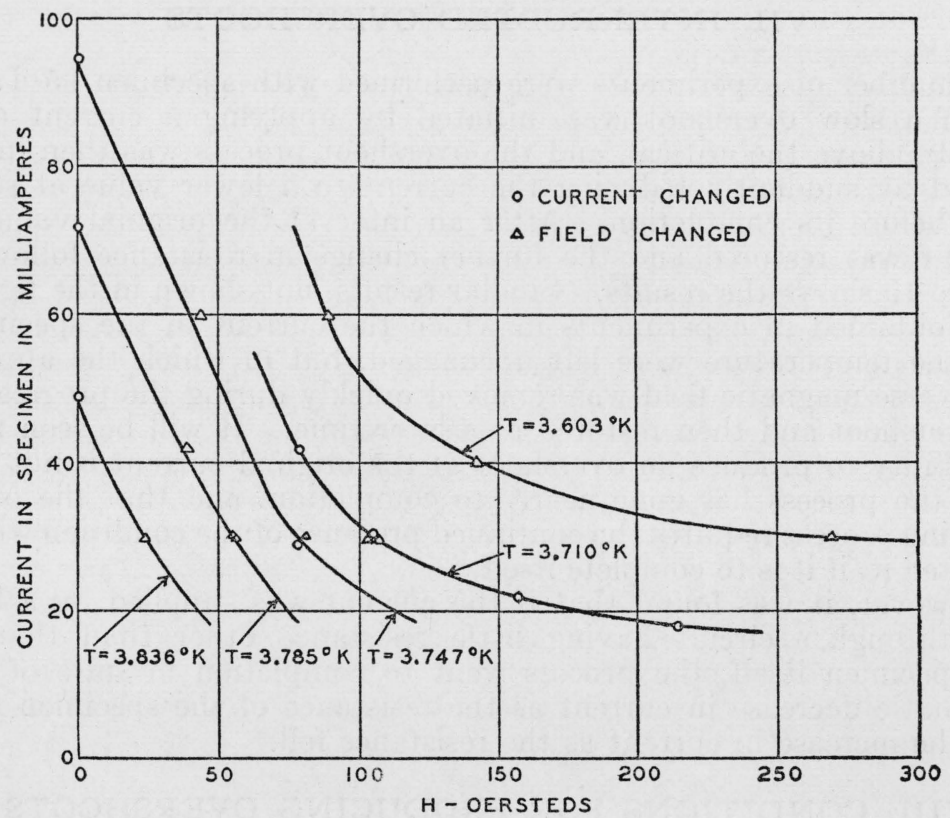

FIGURe 11.-Contours of principal critical surface showing combinations of current and field at which overshoots occur for various fixed temperatures in specimen 95 Ta.

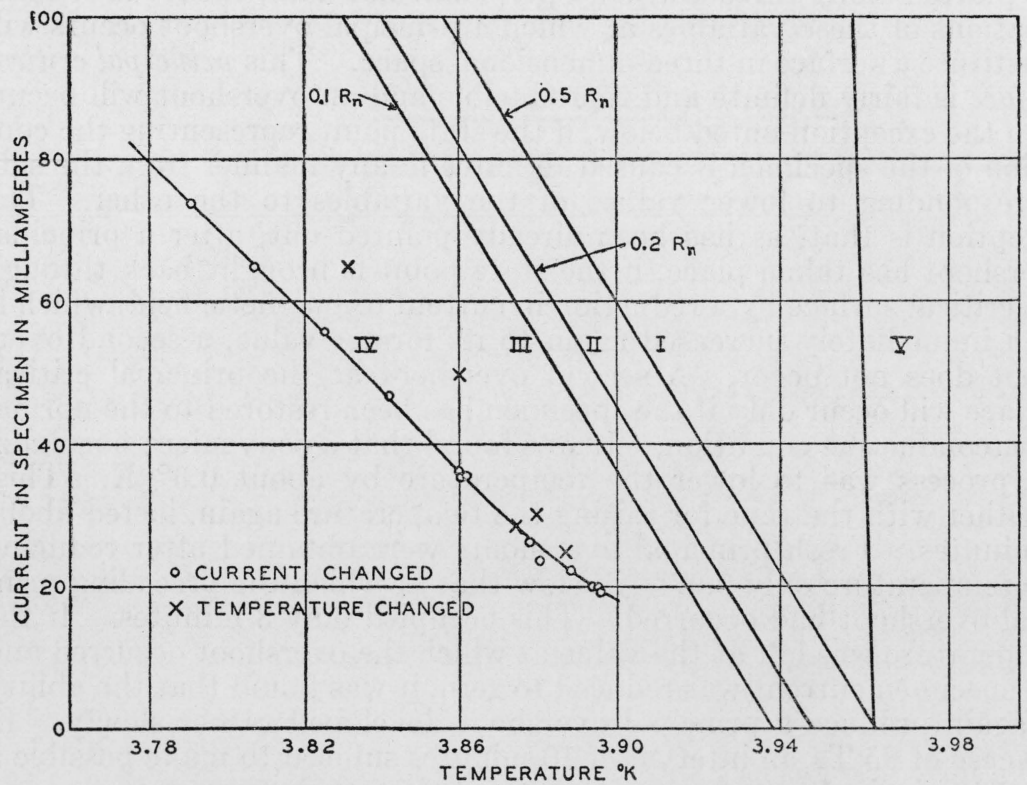

FIGURE 12.-Characteristics of specimen $95 \mathrm{Ta}$.

Curves $I, I I$, and $I I I$ are the loci of combinations of current and temperature for zero external magnetic field at which specimen $95 \mathrm{Ta}$ has $0.5,0.2$ and 0.1 of its normal resistance. Curve $I V$ is the locus of combinations of current and temperature for zero magnetic field at which principal overshoots are initiated. Curve $V$ shows the trend to be expected in Curve $I$ on the basis of the Silsbee hypothesis using the observed mag. netic depression of the transition. 
comparison the temperature-current relation for which $0.5,0.2$, and 0.1 of the normal resistance appears.

At low currents the overshoot locus lies at a temperature about $0.05^{\circ} \mathrm{K}$ below the middle of the normal transition. At large currents there is a temperature depression which is definitely greater than that shown by the lines of constant resistance $(I, I I, I I I)$. The disturbing effects of the overshoots, however, prevent any very precise determination of these latter lines. The observed resistance just before a principal overshoot starts was usually less than 1 percent of the full normal resistance.

In specimen $95 \mathrm{Ta}$ when a considerable magnetic field (100 oersteds) was present and the temperature was correspondingly low, the principal overshoot was smaller than at low fields, but the later secondary overshoots were larger and sometimes exceeded the principal overshoot.

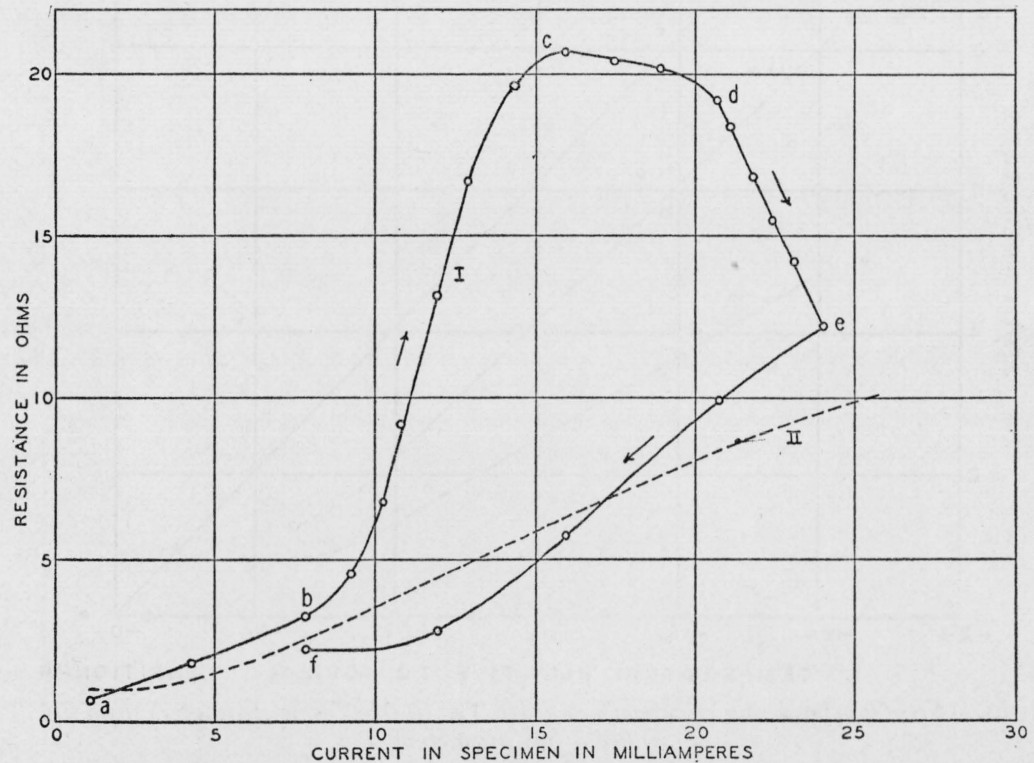

Figure 13.-Curve I shows variation of resistance of specimen $95 \mathrm{Ta}$ with current at constant temperature of $3.926^{\circ} \mathrm{K}$.

From $a$ to $b$ the resistance values are stable in time. From $b$ to $c$ the resistance drifts upward spontaneously after each increase in current. From $c$ to $d$ the net drift is downward. Between $b$ and $d$ ordinates are the final values of resistance. R heostat setting was left unchanged from $d$ to $e$, while the resistance decreased N spontaneously. Curve II shows the estimated position of normal transition curve.

In specimen $10 \mathrm{Ta}$ with large magnetic field, the resistance came in continuously to a very considerable extent before the overshoot, which, in these cases, involved a change of only about 14 percent of the full normal resistance.

For currents of less than $18 \mathrm{ma}$ and hence, if $H=0$, by curve $I V$, figure 12 , at temperatures greater than $3.9^{\circ} \mathrm{K}$, the overshoots in $95 \mathrm{Ta}$ became less marked, though a tendency to slow drifts in resistance was observable down to $8 \mathrm{ma}$. Figure 13 shows the results of an experiment on $95 \mathrm{Ta}$ at $3.926^{\circ} \mathrm{K}$. The value of resistance appeared to be definite and free from spontaneous drifts up to currents of about $8 \mathrm{ma}$. For currents between 8 and $14 \mathrm{ma}$, each increase of current was followed by a drift upward in resistance which lasted for 
several seconds and which seemed similar to the first stage of an overshoot but was not followed by a decrease in resistance. For currents greater than 14 ma, each increase in current was followed immediately by a drift downward in resistance, analogous to the later stage of an overshoot. At 20.8 ma the rheostat setting was left unchanged and a spontaneous decrease in resistance from 19.3 to 12.3 ohms, which occupied about 1 minute, caused the current to increase to $24.1 \mathrm{ma}$. On decreasing the current to $20.8 \mathrm{ma}$ again, the resistance was only $10 \mathrm{ohms}$. The dotted line shows our best estimate of the normal transition curve in this range. With 1 ma only, the normal transition along a reproducible S-shaped, resistance-tempera-

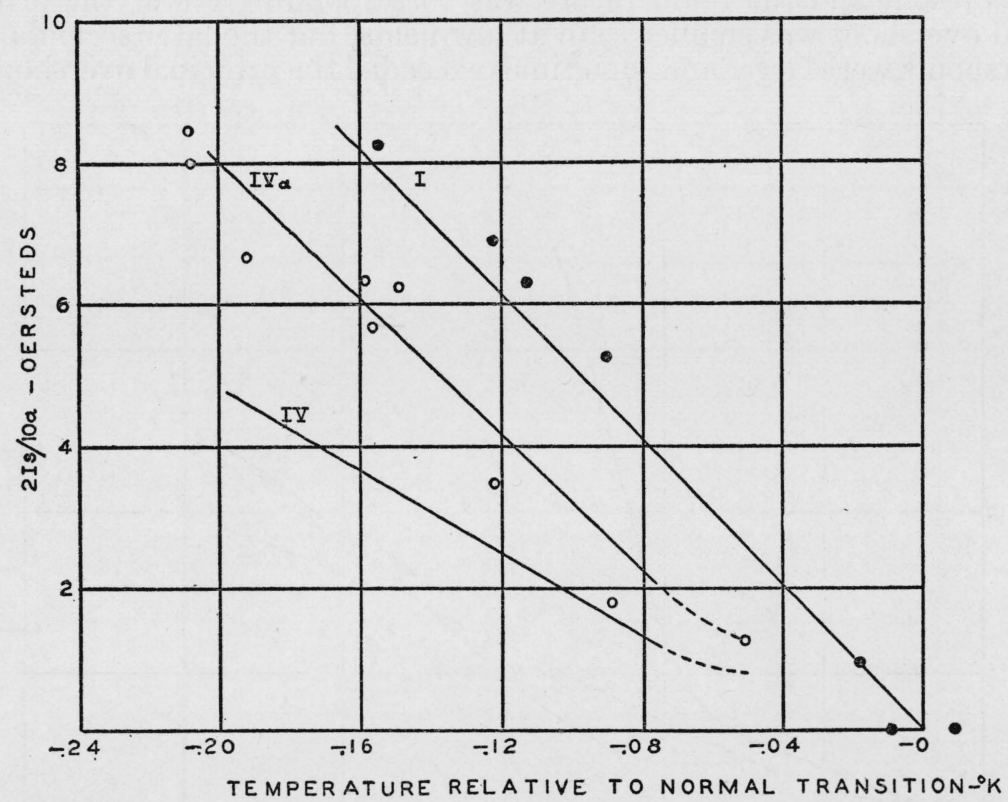

FIgURE 14.-Comparisons of specimens $10 \mathrm{Ta}(0.0127 \mathrm{~cm}$ diameter $)$ and $95 \mathrm{Ta}$ (0.0075 $\mathrm{cm}$ diameter)

Ordinates show the value of $2 I_{s} / 10 a$, where $I$ is the current in the specimen and $a$ its radius. Abscissas show the temperature in digrees Kelvin as measured from the normal transition temperature of each specimen. Solid circles indicate conditions under which specimen $10 \mathrm{Ta}$ permanently attained half its normal resistance. Curve $I$ shows corresponding values for specimen 95 Ta (reproduced from curve $I$ of fig. 12). Open circles indicate conditions under which overshoots occurred in specimen $10 \mathrm{Ta}$. Curve $I V$ shows corresponding values for specimen $95 \mathrm{Ta}$ (reproduced from curve $I V$ of fig. 12). Curve $I V a$ is obtained from curve $I V$ by multiplying each ordinate of the former by 1.7 (the ratio of the diameter of $10 \mathrm{Ta}$ to the diameter of $95 \mathrm{Ta}$ ).

ture curve similar in shape to the resistance-field curves of figure 1 , is observed.

In the tin specimen the principal critical surface approximates a plane, and has the further property that, at a given temperature, the values of specimen current $I_{s}$ and external transverse field $H_{e x t}$, which in combination just produce the principal overshoot, obey the relation $2 I_{s} / 10 a+H_{e x t}=$ constant. It is, therefore, possible to represent the relations among the variables in two dimensions, by plotting as ordinate the total field $H=2 I_{s} / 10 a+H_{\text {ext }}$ against temperature. In figure 2 the values of total field at which the principal overshoot occurred are shown by open circles when the field was entirely caused by current in the specimen, and by open triangles when an external field and a considerable current were both present. 
Measurements were made on specimen $10 \mathrm{Ta}$ primarily for the purpose of finding the relation between the critical current for overshoots and the radius of the specimen by a comparison with data on $95 \mathrm{Ta}$. Unfortunately, the two tantalum wires seem to be somewhat different as is evidenced by the difference in their transition temperatures, which as measured in the absence of an applied field with very small currents, were 4.068 and $3.961^{\circ} \mathrm{K}$, respectively. This difference may perhaps be the result of differences in internal strain in the two wires. A direct comparison of critical currents at the same temperature therefore appears meaningless and instead a comparison has been made at equal depressions below the transition

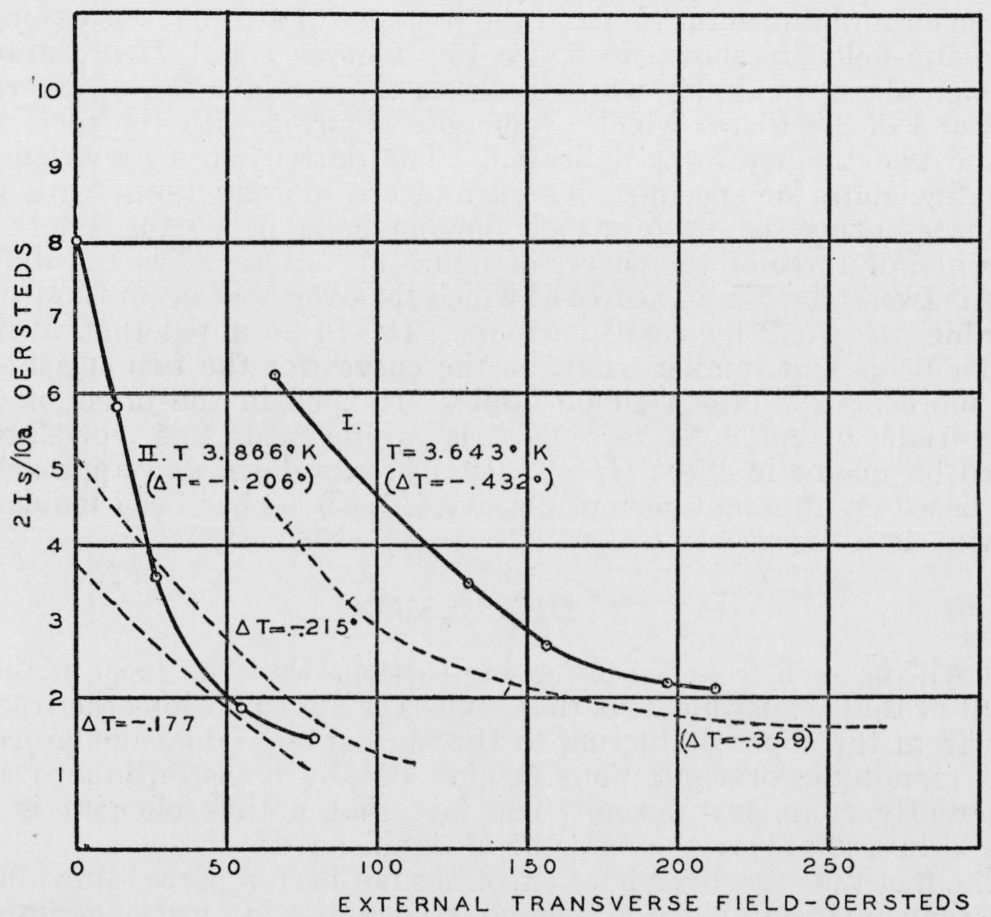

FIGURE 15.-Curves $I$ and II show the combinations of the circular magnetic field caused by the specimen current and the external transverse magnetic field at which overshoots occur in specimen $10 \mathrm{Ta}(0.0127 \mathrm{~cm}$ diameter $)$ at two fixed temperatures.

The dotted curves show similar data for specimen $95 \mathrm{Ta}(0.0075 \mathrm{~cm}$ diameter $)$ reproduced from figure 11 The values of $\Delta T$ are the differences between the temperatures at which the overshoot occurred and the temperature at which $R=R_{n} / 2$ for small currents.

temperatures, as observed with small currents. The comparison is shown in figures 14 and 15 , in which the ordinates are the values of $2 I_{s} / 10 a$. In figure 14 , which gives the data in which no external magnetic field (other than terrestrial) was applied, the open circles show the values of $2 I_{s} / 10 a$ at which $10 \mathrm{Ta}$ showed its principal overshoot, while the solid circles show the values at which half its normal resistance had been permanently developed. Curve $I$ is a reproduction of curve $I$ of figure 12 but with its ordinates expressed in terms of magnetic field, to show the half-resistance curve for $95 \mathrm{Ta}$. 
The agreement of curve $I$ with the solid circles strongly suggests that the permanent attainment of resistance in the two wires of different diameter is connected with the magnetic field produced at the surface by the current. Curve $I V$ is similarly a reproduction of curve $I V$ of figure 12 showing the overshoot locus of $95 \mathrm{Ta}$, and obviously fails to agree with the open circles. However, if the ordinates of curve $I V$ are multiplied by the ratio (1.7) of the diameter of $10 \mathrm{Ta}$ to that of $95 \mathrm{Ta}$, curve $I V a$ results. The agreement of $I V a$ with the open circles indicates that in the two specimens of different diameter at a given temperature interval below their normal transition, the principal overshoot is stimulated when the apparent current density (that is, current in specimen divided by area of cross section) is the same.

The data obtained on $10 \mathrm{Ta}$ in the presence of a transverse external magnetic field are shown in figure 15. Curves $I$ and $I I$ are drawn through the open circles, which indicate the combination of external field and of $2 I_{s} / 10 a$ at which overshoots occurred with the specimen at the two temperatures indicated. The dotted curves give corresponding data for specimen $95 \mathrm{Ta}$ and are reproductions, with the ordinates expressed in terms of the magnetic field caused by the currents, of three of the curves of figure 11. Here $\Delta T$ is the difference between the temperatures at which the overshoot occurs and that at which $R=R_{n} / 2$ for small currents. It will be noted that at the higher fields and smaller currents, the curves for the two specimens fall more or less into a single family arranged in the order of the magnitude of $\Delta T$. As zero field is approached this correlation based on magnetic effect $\left(H=2 I_{s} / 10 a\right)$ breaks down and approaches one based on apparent current density $\left(I_{s} / \pi a^{2}\right)$, as has been indicated previously in figure 14 .

\section{DISCUSSION}

It will be seen from the foregoing sections that the most striking result of these experiments is that under certain conditions the transition from the superconducting to the normal state does not proceed in a monotonic or continuous fashion but by a discontinuous and apparently complex process. The fact that a time element is involved in this process may also be of significance.

The fact that this overshoot effect has not been reported previously is perhaps attributable to the circumstance that in most experiments with superconducting wires, the current used to measure the resistance of the specimen has not been sufficiently large.

We may consider (as is very probable) that various parts of these polycrystalline specimens are not exactly equally favorably situated for exhibiting superconduction, and hence reach their thresholds for overshoots, as well as for the normal transition, at slightly different temperatures, fields, or currents. The overshoot phenomena may then be conveniently described in a self-consistent fashion by considering that in going from the superconducting to the normal resisting state, under the conditions which produce overshoots, the material passes successively through three distinct stages.

As temperature, field, or current is raised before the principal overshoot is reached, the bulk of the material is in the superconducting state, stage $A$. The specimen, as a whole, then has a small but measurable resistance. At the beginning of the principal overshoot, 
conditions became such that for part at least of the specimen stage $A$ is no longer stable, and this part passes to stage $B$. This stage which each part of the specimen passes through at the crest of its overshoot, is characterized by a relatively high resistance and a tendency to pass over spontaneously into a new state also of zero resistance, stage $C$. Stage $C$ differs from stage $A$ in the important respect that in it the overshoot phenomenon can not be initiated. The progress from $B$ to $C$ takes place more slowly than that from $A$ to $B$.

The subsequent overshoots then correspond to the transitions of other portions of the specimen which remained in stage $A$ during the preceding overshoots. On this basis, there is no fundamental difference in the mechanism of the principal and the other overshoots.

If the current is interrupted before all the material which would otherwise be involved in a single overshoot has reached stage $B$, some of it will be still in stage $A$ and be ready to start a new overshoot when the current is again established. On the other hand, if all the material has reached stage $B$, an interruption of the current will not be followed by an overshoot but merely by further progress from $B$ to $C$.

Since the specimen has been considered to be somewhat inhomogeneous, the production of a large overshoot by a small step in temperature, field, or current, suggests strongly that the passage of a part of the specimen from stage $A$ to stage $B$ propagates itself to adjacent parts which were nearly but not quite past their stability limits. This view that the phenomenon propagates itself is also consistent with the observation that a fast overshoot results from a large step beyond the critical frequency which can throw a larger number of centers beyond their limit of stability, while only a slow response is obtained from a small step which can stimulate only a much smaller number of centers from which the disturbance must be propagated over greater distances. Also a large step may well directly speed the propagation rate (fig. 4).

The view that different parts of the specimen reach their thresholds at slightly different temperatures, fields, or currents, implies that the resistance shown by the specimen before a principal overshoot is caused by the existence of sections which have already reached the normal resisting state, in series with other sections still superconducting. This preliminary resistance was particularly large in the case of specimen $10 \mathrm{Ta}$ when in a magnetic field. Only those sections of the wire which are still in the superconducting stage $A$ are supposed to be capable of exhibiting the overshoot phenomenon. In these sections it is to be presumed that by reason of the Meissner effect, the current is distributed in a thin layer around the outer surface of the wire.

If each portion of the specimen as it reaches stage $B$ has temporarily its normal resistance, it would be expected that the sum of all the increases of resistance in these experiments would amount to double ${ }^{10}$

\footnotetext{
10 The 4 th and 5 th experiments on specimen $95 \mathrm{Ta}$ listed in table 2 seem to be exceptions to this. In the 4 th experiment, the decrease in resistance following a third overshoot at 80 ma was abnormally great suggesting that the (manual) control of the bath temperature may have been unable to adjust for the sudden fluctuations in heat supply and allowed a temporary drop in temperature permitting some of the material to return to stage $A$. In the 5 th experiment the increases in current were small with the result that the principal return to stage $A$. In the 5th experiment the increases in current were small with the result that the principal for 2 seconds after each overshoot to permit stage $C$ to be more fully attained, and it may be that the long duration of the experiment permitted some of the material to pass back to stage $A$ and go through the process again.
} 
the normal resistance of the specimen, since the changes from $A$ to $B$, as well as those from $C$, to the normal resisting state will be included. If, however, the external conditions are advanced rapidly, there is not time for the change from $B$ to $C$ to proceed to completion, and the sum of the increases in such an experiment is less than double the normal resistance.

After the completion of an overshoot the specimen has, in general, about as low a resistance as before it occurred, so that we may again expect that it contains sections of normally resisting material in series with sections of zero resistance, the former being the same as those existing previous to the overshoot and hence having been unaffected by it. The zero-resistance sections, however, are obviously different from the corresponding sections in stage $A$ since they have lost the ability to overshoot at the originally critical conditions. It would seem possible that the distinction may be in a fundamental difference in the distribution of current over the cross section of the wire in the two stages. In stage $A$ this distribution must (on the basis of the Meissner effect) be confined to the surface of the wire. In contrast to this the zero-resistance sections of the specimens in stage $C$ may be thought of as a combination, in parallel, of normal resisting material and of superconducting filaments or laminas, as has been suggested by Gorter and other theoretical workers in a different connection. Such a more nearly uniform distribution of current over the cross section of the wire might well bring into service particularly favorably situated portions which had been inactive in the regime of stage $A$. It must be recognized, however, that this regime suggested as a possibility for stage $C$ could not persist unless there is a sufficient range of threshold conditions to permit some of the outer portions to remain superconducting in spite of the somewhat increased magnetic field resulting from the new current distribution.

The propagation through the specimen of an initial disturbance may be reasonably explained as follows: when one volume element unfavorably situated for superconduction and located at the surface is subjected to a magnetic field and temperature which exceed its threshold it becomes resisting. The flow lines of current in avoiding this spot will necessarily be somewhat bent, with a corresponding local increase in magnetic field in adjacent volume elements; these, unless they possess abnormally high thresholds will in turn become resisting and increase the initial disturbance, as is required for propagation. With small currents the additional local field resulting from a given distortion of the flow lines will be small and the propagation of the disturbance will be readily checked by a chance group of favorably situated volume elements. This is in accord with the observation that a considerable current is requisite for the production of overshoots.

The recent experiments of de Haas and Guinau ${ }^{11}$ on the penetration of magnetic field into a superconducting tin sphere show very definitely a complete breaking-down of one regime of macroscopic currents into a distinctly different system. It would seem that this process may be rather closely analogous to the overshoot phenomenon.

Washington, January 8, 1937.

\footnotetext{
11 Physica 3, 182 and 534 (1936).
} 